\title{
THE ROLE OF MRI IN CLINICALLY SUSPECTED APPENDICITIS DURING PREGNANCY
}

André Luis Bergamaschi Zilio', Juliana Avila Duarte ${ }^{1,2}$, Fabricio Bergelt Souza ${ }^{1,2}$, Letícia Maffazzioli Santos ${ }^{1,2}$

Clin Biomed Res. 2015;35(4):248-249

1 Tomoclínica. Canoas, RS, Brazil.

2 Serviço de Radiologia, Hospital de Clínicas de Porto Alegre (HCPA). Porto Alegre, RS, Brazil.

Corresponding author: Juliana Avila Duarte

E-mail: juavila2003@yahoo.com.br Tomoclínica

Rua Anita Garibaldi, 194. 92010-100, Canoas, RS, Brazil.
A 31-year-old female with approximately 20 weeks' gestation presented to the emergency department of Hospital de Clínicas de Porto Alegre (HCPA) reporting pain in the lower abdomen radiating to the right iliac fossa. After clinical and laboratory examination, the clinical diagnosis of appendicitis was suspected. An abdominal ultrasound was performed, but imaging study was inconclusive because it was not possible to visualize the appendix. Then, diagnostic magnetic resonance imaging (MRI) of the abdomen and pelvis was performed with the patient in apnea and without contrast injection, using fast acquisition T1-weighted (T1WI) and T2 weighted (T2WI) sequences that revealed signs of appendicitis (figures 1 and 2). The intraoperative findings were purulent fluid in the right iliac fossa and appendix with necrotic appearance and without signs of perforation. The pathological diagnosis was acute suppurative appendicitis, with signs of inflammation around the viscera.

Acute appendicitis complicates approximately one of 766 pregnancies and is the most common nonobstetric surgical emergency in pregnancy ${ }^{1}$. Acute appendicitis in pregnant women has been associated with premature labor and fetal and maternal death, particularly when perforation with peritonitis occurs $^{2}$. In pregnant women the enlarged uterus can alter the position of the abdominal contents and thus make sonography and clinical diagnosis more difficult. Computed tomography (CT) can be performed in such cases, but it involves a considerable amount of radiation. A typical dose for an abdominal CT examination is on the order of $10 \mathrm{mSv}$ dose, which is lower than the amount of risk to pregnant women. However, the recommendation is to avoid exposure to ionizing radiation, when possible. That is why we try to use ionizing radiation-free methods such as ultrasound and MRI. The routine use of diagnostic CT for benign diseases such as appendicitis raises the question whether the diagnosis can be obtained by other radiologic means, especially in pregnant women and even more when the fetus is exposed to direct beam radiation. MRI has been described as a valuable technique for the evaluation of patients with suspected acute appendicitis.

The MRI criteria that exclude appendicitis are a normal appendix of less than $6 \mathrm{~mm}$ or an appendix with a diameter of more than $6 \mathrm{~mm}$ with no evidence of periappendicitis. Appendicitis should be suspected in the presence of an appendix with a diameter greater than $6 \mathrm{~mm}$ combined with changes in peritoneal fat and high signal intensity on T2-weighted and fat suppression images and low signal intensity on T1-weighted images. When the appendix is seen in its short axis, a typical target sign is seen; lumen with high signal intensity on T2-weighted and fat-suppressed images and low signal intensity on T1-weighted images; and appendiceal wall with hypointense signals on T1-weighted images and slightly hyperintense signals on T2-weighted images. Appendicolith, when present, is seen as a rounded structure with no signal. An examination of abdominal and pelvic MRI seems to be a good alternative for pregnant patients with suspected acute abdomen. No known biologic risks are associated with MRI ${ }^{1}$. 


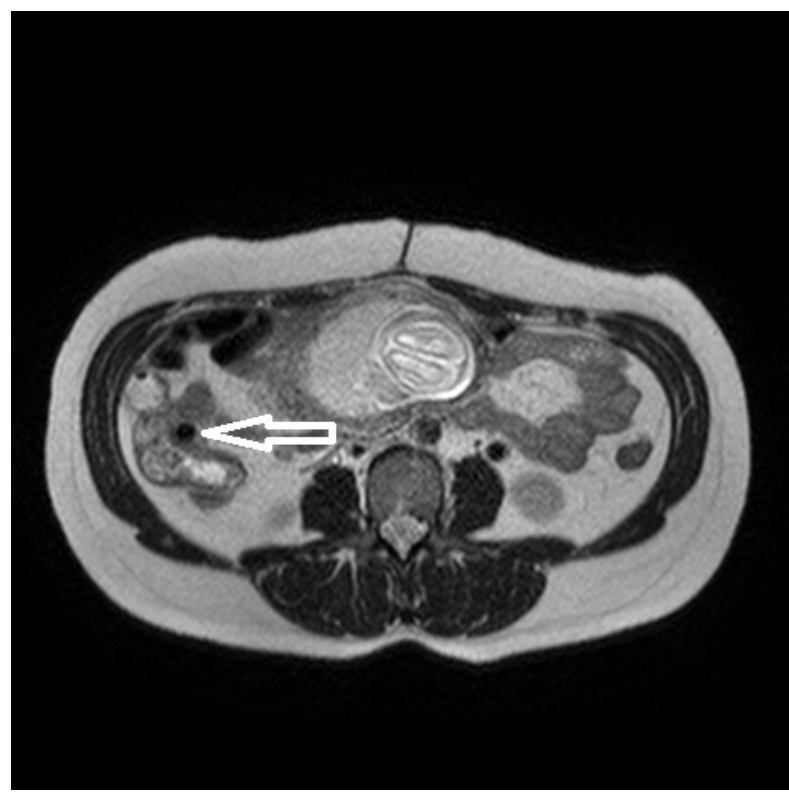

Figure 1: Axial T2WI sequence with fat suppression (spectral attenuated inversion recovery, SPAIR) demonstrating the appendiceal wall at the base of the appendix, with hypointense T2 signals.

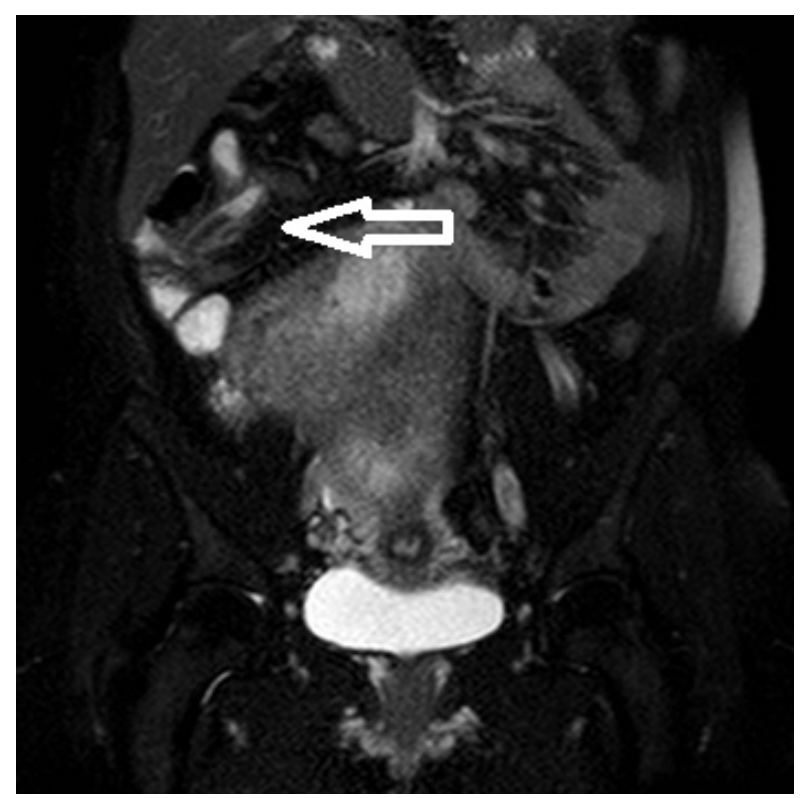

Figure 2: Coronal T2WI sequence with fat suppression (spectral attenuated inversion recovery, SPAIR) demonstrating the enlarged appendix and mesoappendix with hyperintense signals related to mild edema.

\section{REFERENCES}

1. Cobben LP, Groot I, Haans L, Blickman JG, Puylaert J. MRI for clinically suspected appendicitis during pregnancy. AJR Am J Roentgenol. 2004;183(3):671-5. http:// dx.doi.org/10.2214/ajr.183.3.1830671. PMid:15333354.

2. Oto A, Srinivasan PN, Ernst RD, Koroglu M, Cesani F, Nishino
T, et al. Revisiting MRI for appendix location during pregnancy. AJR Am J Roentgenol. 2006;186(3):883-7. http:// dx.doi.org/10.2214/AJR.05.0270. PMid:16498125.

Received: Sept 30, 2015 Accepted: Nov 20, 2015 